\title{
A Teoria da Aprendizagem Significativa e o jogo
}

\author{
Felipe do Espírito Santo Silva-Pires \\ Valéria da Silva Trajano \\ Tania Cremonini de Araujo-Jorge \\ Instituto Oswaldo Cruz/Fiocruz (Brasil)
}

\section{Resumo}

Este estudo tem como objetivo apresentar os princípios da Teoria da Aprendizagem Significativa e as propriedades do jogo, e discutir como ambos interagem. Segundo a Teoria, a aprendizagem significativa ocorre quando novos conhecimentos se relacionam de modo não-arbitrário e substantivo com a estrutura cognitiva do aprendiz. $\bigcirc$ jogo educacional requer dialogicidade, senso crítico, e está baseado na realidade daqueles que o praticam, cujos conhecimentos prévios se fazem necessários para que o jogador possa construir novos saberes por meio de uma atividade divertida, dinâmica e interpretativa de conceitos abstratos e complexos. Constatamos que os jogos possibilitam uma aprendizagem significativa, visto que atendem a diferentes etapas do desenvolvimento cognitivo, têm sua qualidade relacionada às interações estabelecidas entre seu objeto de conhecimento e a estrutura cognitiva do educando, e permitem a apresentação de conceitos centrais para a aquisição de novos conhecimentos mediante uma linguagem clara e objetiva.

Palavras-chave: Jogo. Aprendizagem significativa. Lugares comuns da educação. Conceitos estruturantes.

\section{Theory of Meaningful Learning and the game}

\section{Abstract}

This study presents the principles of Theory of Meaningful Learning and the properties of the game, and discuss their interaction. According to Theory, meaningful learning occurs when new knowledge is related in a non-arbitrary and substantive way to the cognitive structure of the learner. The educational game requires dialogue, critical sense, and is based on the reality of those who practice it, whose previous knowledge is necessary so that the player can build new knowledge through a fun, dynamic and interpretive activity of abstract and complex concepts. We found that games enable meaningful learning, since they attend different stages of cognitive development, have their quality related to the interactions established between their object of knowledge and the cognitive structure of the student, allowing the presentation of central concepts for the acquisition of new knowledge through clear and objective language.

Keywords: Game. Meaningful learning. Common places of education. Structural concepts 
A Teoria da Aprendizagem Significativa e o jogo

\section{Teoría del Aprendizaje Significativo y el juego}

\section{Resumen}

Este estudio tiene como objetivo presentar los principios de la Teoría del Aprendizaje Significativo y las propiedades del juego, y discutir cómo ambos interactúan. Según la Teoría, el aprendizaje significativo se produce cuando el nuevo conocimiento se relaciona de manera no arbitraria y sustantiva con la estructura cognitiva del alumno. El juego educativo requiere diálogo, sentido crítico, y se basa en la realidad de quienes lo practican, cuyo conocimiento previo es necesario para que el jugador construya conocimiento nuevo a través de una actividad divertida, dinámica e interpretativa de conceptos abstractos y complejos. Descubrimos que los juegos permiten un aprendizaje significativo, ya que cumplen con diferentes etapas del desarrollo cognitivo, tienen su calidad relacionada con las interacciones establecidas entre su objeto de conocimiento y la estructura cognitiva del alumno, y permiten la presentación de conceptos centrales para la adquisición de otros nuevos. conocimiento a través de un lenguaje claro y objetivo.

Palabras clave: Juego. Aprendizaje significativo. Lugares comunes de la educación. Conceptos estructurantes.

\section{Aprendizagem significativa: conceito, histórico e elementos centrais para o educador}

Uma das teorias construtivistas que pode auxiliar os processos de ensino e aprendizagem é a Teoria da Aprendizagem Significativa de David Paul Ausubel. A Teoria foi apresentada pela primeira vez em 1963 no livro "The psychology of meaningful verbal learning". Em 1968, Ausubel voltou a escrever sobre a Teoria no livro "Educational Psycology: a cognitive view", que contou com a participação de Joseph Novak e Helen Hanesian (LEMOS, 2012).

Segundo Ausubel (2003), a aprendizagem significativa ocorre quando há a associação entre o conhecimento prévio do indivíduo, ou subsunçor, com um material potencialmente significativo, de forma não-arbitrária e substantiva, possibilitando a construção de significados. A construção dos subsunçores está relacionada à maturidade cognitiva do aprendiz que determina a prontidão cognitiva capaz de promover mudanças em sua estrutura cognitiva. Dessa forma, os novos conhecimentos passam a ter significados, com ou sem auxílio de organizadores prévios. Com o tempo, as informações podem ser esquecidas, mas o indivíduo internaliza o conteúdo ao aprender significativamente produzindo vestígios estáveis que permitem o seu resgate. A aprendizagem significativa pode ser representacional, conceitual e proposicional, e ocorrer por 
recepção ou descoberta. No entanto, a aprendizagem por recepção tende a ser mecânica quando há apenas uma repetição de conceitos (AUSUBEL, 2003) (Figura 1).

\section{Figura 1}

\section{Mapa conceitual sobre Aprendizagem Significativa}

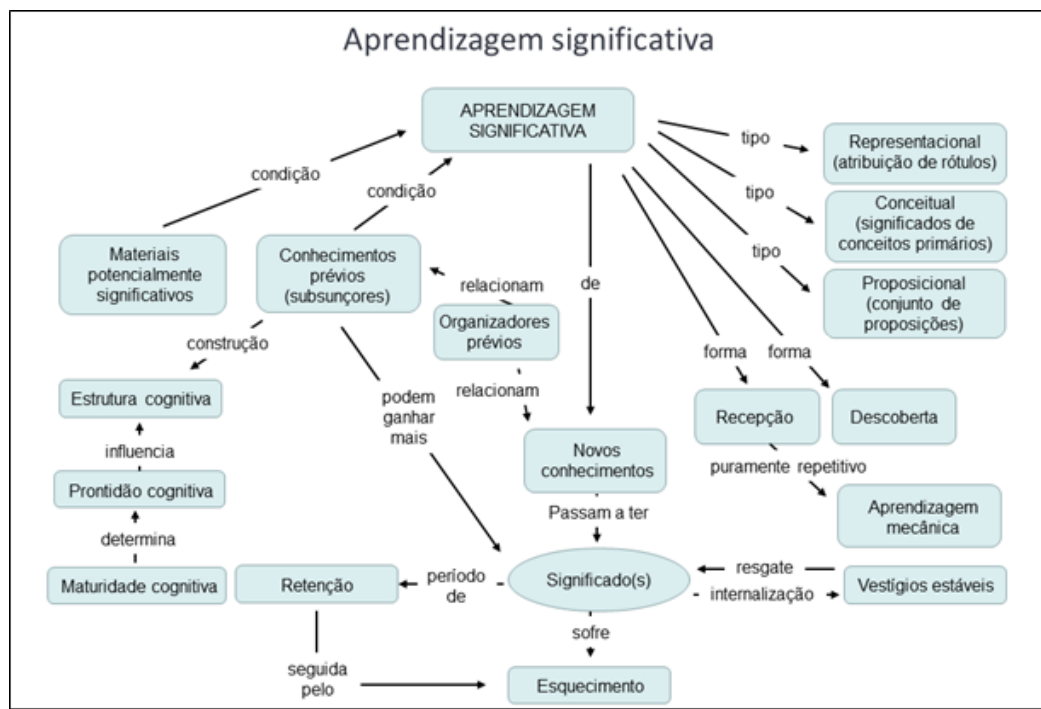

Fonte: elaborado pelos autores.

material potencialmente significativo pode ser compreendido como a representação do conteúdo em seus diferentes formatos, como ideias, modelos mentais, representações sociais ou conceitos, desde que possua significado para o estudante (MOREIRA, 201 1). Esse material deve estabelecer uma lógica capaz de relacionar o conteúdo apresentado com o conhecimento prévio de um indivíduo ou grupo de pessoas (NOVAK, 2000). O significado atribuído ao novo conhecimento depende da relevância de seus conceitos e proposições. Os conceitos podem ser definidos como um rótulo concedido a um determinado objeto ou acontecimento, e as proposições como duas ou mais palavras combinadas que formam uma afirmação sobre um acontecimento, objeto ou ideia (NOVAK, 2000).

A definição de um conceito está relacionada à capacidade de abstração que pressupõe uma metáfora (DIAS, 201 1). Ao jogar, o indivíduo manipula a realidade, ou seja, transforma o real por meio da imaginação como faz com 
a linguagem, primeiro instrumento criado pela imaginação humana para dar significado aos elementos da natureza. Ao jogar com as palavras o homem brinca com a realidade por meio de representações simbólicas, que constituem a gênese da metáfora e consequentemente possibilitam a construção do conhecimento (DIAS, 2011 ; HUIZINGA, 2014).

\section{Jogos e seu potencial para a aprendizagem significativa}

$\bigcirc$ potencial dos jogos para uma aprendizagem significativa coloca este recurso didático em destaque tanto no ensino quanto na pesquisa sobre o ensino. $\bigcirc$ jogo está presente desde o início da história da humanidade, e ultrapassa os princípios da atividade puramente física ou biológica $(H U I Z I N G A$, 2014 ). Sua intensidade e poder de fascinação não podem ser explicados por análises biológicas. Além disso, é uma atividade que envolve tensão, alegria e diversão. Esse último elemento define a essência do jogo e resiste a análises e interpretações lógicas.

$\bigcirc$ conceito de jogo está relacionado às suas principais características. $\bigcirc$ jogo é uma atividade voluntária, onde a liberdade reside no prazer de brincar. Um outro aspecto do jogo é a evasão temporária da realidade, pois é capaz de promover a imersão do jogador num dado momento. $\bigcirc$ jogo apresenta regras que são absolutas e indiscutíveis e tem como função a luta ou a representação. Outras características gerais são a tensão e a incerteza, que se apresentam diante dos desafios, e da vontade de vencer. Huizinga resume as características formais do jogo da seguinte forma:

○ jogo é uma atividade ou ocupação voluntária, exercida dentro de certos e determinados limites de tempo e de espaço, segundo regras livremente consentidas, mas absolutamente obrigatórias, dotado de um fim em si mesmo, acompanhado de um sentimento de tensão e de alegria e de uma consciência de ser diferente da 'vida cotidiana' (HUIZINGA, 2014, p. 33).

Kishimoto (2011) apresenta uma definição mais simples para o conceito de jogo, que pode ser expresso como o resultado de um sistema linguístico dentro de um contexto social, dotado de um sistema de regras com o sentido de alcançar um determinado objetivo. Em seus trabalhos, Kishimoto 
$(2011,2016)$ destaca ainda a diferença entre os termos jogo, brinquedo e brincadeira. Brinquedo é o objeto, brincadeira, uma conduta estruturada por regras e jogo, uma interação entre o brinquedo e a brincadeira.

Para que uma aprendizagem significativa aconteça, deve-se considerar três conceitos que estão interligados: estrutura cognitiva, prontidão cognitiva e maturidade cognitiva. A estrutura cognitiva pode ser influenciada por variáveis como disponibilidade, estabilidade, clareza e capacidade de discriminação dos subsunçores e pela prontidão cognitiva do indivíduo (AUSUBEL, 2003). Significados claros, estáveis e organizados dificultam o surgimento de equívocos e mantêm a força de dissociabilidade que influencia na retenção-esquecimento do conteúdo. A prontidão cognitiva não depende da presença de subsunçores, mas da maturidade cognitiva responsável pela probabilidade de êxito em uma determinada tarefa de aprendizagem. Já a maturidade cognitiva varia de acordo com experiências culturais, subculturais e idiossincráticas (AUSUBEL, 2003). No entanto, o jogo antecede e constitui a cultura, pois este sempre fez parte da vida dos animais e todas as definições de cultura pressupõem a sociedade humana (HUIZINGA, 2014). Isso demonstra a importância do jogo na construção da maturidade cognitiva. Além disso, as diferentes etapas do desenvolvimento cognitivo integram e precedem a seguinte, acompanhando o ritmo e as características cronológicas de cada indivíduo, e induzem o nível de complexidade dos jogos de cada faixa etária (GARON, 1998).

Uma fase complementar à aprendizagem significativa é a retenção-esquecimento do conteúdo. Aquele conteúdo que foi apreendido e ancorado a algum subsunçor é retido pelo indivíduo (AUSUBEL, 2003). A retenção do conteúdo é medida pela força de dissociabilidade estabelecida com a estrutura cognitiva do indivíduo. A redução na utilização de determinado conhecimento faz com que a força de dissociabilidade comece a diminuir. Quando a dissociabilidade reduz ao ponto de alcançar níveis críticos - limiar de disponibilidade -, ocorre o esquecimento do conteúdo ou, segundo Ausubel, a subsunção obliterante. A aprendizagem significativa se destaca positivamente em relação à retenção de significados quando comparada à memorização. Na aprendizagem significativa, a relação estabelecida entre os subsunçores e as novas ideias do material educacional protege os significados de interferências arbitrárias e literais devido à alta estabilidade. A não-arbitrariedade e subjetividade também promovem a retenção de um maior volume de material 
por mais tempo. Ao destacar os significados do material durante a aprendizagem, há a internalização de conceitos e a formação de "vestígios estáveis", que facilitam o resgate do conhecimento construído (AUSUBEL, 2003). Assim, a qualidade de um jogo educacional está relacionada à sua capacidade de promover associações entre a estrutura cognitiva do indivíduo e o objeto de conhecimento relacionado ao jogo, de forma que os significados se destaquem e possam ser retidos pelo estudante.

Nesse sentido, o uso de imagens para ilustrar os conceitos abordados nos jogos educacionais facilita e aumenta a capacidade de apreensão e solução de problemas pelos educandos (MAYER, 2005). As imagens podem despertar sentidos e emoções relevantes para a construção de novos saberes (AMORIM; SILVA, 2016; OLIVEIRA; SOUZA, 2014). Contudo, essa junção entre texto e imagem não deve ocorrer de forma aleatória. As imagens do material educacional precisam ter valor didático e estar de acordo com a carga cognitiva do educando (MAYER, 2005).

Em algumas situações há um grande distanciamento entre o conhecimento prévio e o material potencialmente significativo. Então, são utilizados organizadores prévios capazes de mediar a aproximação entre o que o apren6 diz já sabe e o que precisa saber. Os organizadores prévios são materiais que estabelecem alguma relação lógica com o novo conhecimento, mesmo que não seja o conteúdo a ser ensinado (AUSUBEL, 2003).

A aprendizagem significativa é classificada como representacional, conceitual e proposicional. A aprendizagem representacional é a atribuição de rótulos (nomes, sinais ou símbolos) a objetos, acontecimentos ou conceitos. A aprendizagem conceitual dá-se de duas formas: formação e assimilação conceitual. A formação conceitual, geralmente realizada por crianças pequenas, é a construção de significados de conceitos primários, como cão, mamãe e comer, por meio de experiências concretas. A assimilação conceitual é a aquisição de conceitos secundários, visíveis ou abstratos. A aprendizagem proposicional ocorre quando um conjunto de proposições atribui significado a um determinado conceito. A variedade de significados associados a um conceito é consequência da relação dos subsunçores com as novas proposições (AUSUBEL, 2003; LEMOS, 2012 ; NOVAK, 2000). O jogo pode facilitar a apreensão do conhecimento nos três tipos de aprendizagem significativa, uma vez que existem diferentes categorias de jogos, como de exercício, simbólicos, de acoplagem e de regras simples ou complexas (GARON, 1998). No entanto, 
Felipe do Espírito Santo Silva-Pires | Valéria da Silva Trajanol Tania Cremonini de Araujo-Jorge

é preciso identificar todos os aspectos do jogo selecionado em função de sua correspondência com os interesses do tipo de aprendizagem.

A aprendizagem significativa pode ocorrer por recepção ou descoberta. A aprendizagem por recepção envolve a apresentação do conteúdo ao estudante em sua forma final, e a aprendizagem por descoberta requer autonomia do educando para observar, compreender e integrar um novo conteúdo à sua estrutura cognitiva. Ambas podem levar à aprendizagem significativa, mas tanto o tempo como a complexidade do conteúdo são fatores que podem limitar a aprendizagem por descoberta (NOVAK, 2000). Dessa forma, a utilização de jogos que proporcionem uma aprendizagem por recepção se torna uma boa opção para trabalhar o conteúdo, uma vez que a prática docente geralmente é condicionada pelo "tempo de aula", e a ludicidade facilita os processos de ensino e aprendizagem.

A aprendizagem significativa depende de dois princípios importantes, a diferenciação progressiva e a reconciliação integradora. A diferenciação progressiva demonstra a relação hierárquica do conhecimento, pois prevê a apresentação de conceitos mais gerais e inclusivos que se diferenciam em conceitos mais específicos e menos inclusivos. A reconciliação integradora ocorre quando as semelhanças e diferenças entre um novo conceito e os subsunçores são percebidos pelo estudante e incorporados à sua estrutura cognitiva (AUSUBEL, 2003). Ambos destacam a importância de conceitos centrais que facilitem a compreensão do estudante. Esses conceitos, chamados estruturantes, possibilitam a transformação do sistema cognitivo, levando o indivíduo a adquirir novos conhecimentos e a modificar o conhecimento construído anteriormente (GAGLIARDI, 1986). Por isso, os conceitos estruturantes são essenciais nos jogos educacionais.

Outros pensadores da educação demonstraram interesse e contribuíram significativamente para a Teoria da Aprendizagem Significativa. Joseph Novak $(1977,2000$ ) acrescentou à Teoria o aspecto afetivo na aprendizagem, a negociação de significados e a ideia da avaliação como um quinto elemento educativo. Já Bob Gowin (1981) contribuiu com a importância do compartilhamento de significados e da intencionalidade do estudante para apreender. Por fim, Marco Antonio Moreira (2000; 2005) trouxe para a discussão a necessidade de uma aprendizagem significativa crítica. 
Novak (1977) e Gowin (1981) acrescentaram à Teoria da Aprendizagem Significativa os chamados "lugares comuns da educação". Segundo Schwab (1973), um evento educativo depende da integração de quatro lugares comuns igualmente importantes: professor, aluno, conteúdo e contexto. As ideias de Schwab levaram Novak a pensar na aprendizagem como um conjunto de experiências cognitivas, afetivas e motoras. Segundo Novak (201 1), o conhecimento é construído com base na negociação de significados entre o professor e o aluno e está sujeito aos sentimentos presentes nessa relação. Nesse sentido, os jogos podem promover a aprendizagem, pois os estudantes vivenciam sentimentos de tensão e alegria durante as partidas, e a ludicidade é capaz de estimular o diálogo e a troca de informações durante um evento educacional. A avaliação é proposta por Novak como um quinto elemento do evento educativo dada a sua importância para a aplicabilidade da Teoria e para a vida (LEMOS, 2012).

A avaliação é condição fundamental para a aprendizagem significativa. A necessidade de identificarmos o conhecimento prévio do estudante, de acompanharmos os desdobramentos dos processos de ensino e aprendizagem, e de verificarmos se os objetivos propostos foram alcançados demonstram a 8 sua importância. Portanto, as avaliações não devem se limitar a atribuir escores à uma aprendizagem de curto prazo, mas avaliar início, meio e fim de uma sequência instrucional. Ao avaliar o estudante, devem ser verificados o desempenho individual, e a relação desses valores com a média alcançada pela turma e com o padrão absoluto estabelecido pelo professor. As avaliações precisam fornecer informações retroalimentadoras que permitam a identificação da eficiência das práticas pedagógicas e dos recursos didáticos ljogos, músicas, internet) (AUSUBEL; NOVAK; HANESIAN, 1980).

A leitura de Gowin sobre os "lugares comuns da educação" aponta o compartilhamento de significados realizado pela tríade professor-aluno-conteúdo como um predecessor da aprendizagem significativa. $\bigcirc$ evento educativo segue as etapas de apresentação dos significados, negociação, compartilhamento e aprendizagem significativa. $\bigcirc$ compartilhamento envolve a captação de significados e, caso não ocorra, o conhecimento negociado não é apreendido. Entretanto, o estudante precisa querer aprender significativamente, pois aprender exige um esforço pessoal e intencional (LEMOS, 2012). Os jogos são atividades que promovem a integração entre os "lugares comuns da educação", pois estimulam o diálogo entre professor-aluno-conteúdo, e facilitam a 
Felipe do Espírito Santo Silva-Pires | Valéria da Silva Trajanol Tania Cremonini de Araujo-Jorge

apresentação dos conceitos pelo uso de uma linguagem clara e objetiva, seja ela textual, visual ou sensorial. Os diferentes formatos de jogos contemplam contextos diversos e o material pode ser adaptado à realidade do estudante.

\section{O jogo e sua inserção nas culturas e na educação}

A cultura se estrutura por representações simbólicas coletivas que são criadas e recriadas pelos indivíduos a partir de interações com a realidade física e social (HUIZINGA, 2014). As formas mais complexas da vida social, como a religião, o direito, a guerra, a política e a arte, têm suas raízes no jogo. A religião e a arte nos transportam para além de um plano de pensamento lógico, explorando nossa imaginação em um jogo de "faz de conta" no qual captamos e representamos o ambiente. $O$ direito pode ser visto como uma competição ou batalha verbal, submetido a um sistema de regras e limitações de tempo e espaço, onde os adversários desejam a vitória, independentemente da busca pela justiça. A guerra em seu aspecto lúdico se assemelha ao duelo judiciário - uma luta pelo direito e poder. Na política, as características lúdicas estão presentes na rivalidade parlamentar (HUIZINGA, 2014).

$\bigcirc$ ganhar está estritamente ligado à ideia de jogo. No momento em que duas pessoas disputam para atingir determinado objetivo, tem início uma competição. Esta pode assumir diferentes formas, como um oráculo, uma aposta, um julgamento e seu resultado pode ser determinado pela sorte, força, destreza, conhecimento, mas sempre se tratará de um jogo, independentemente de como se apresente (HUIZINGA, 2014). A competição está presente nas relações de trabalho, no ambiente acadêmico, nas relações interpessoais e nos jogos de forma mais evidente, onde uma pessoa ou um grupo tem como objetivo ser melhor que seu oponente (CARVALHO, 2015). $O$ contraponto da competição é a cooperação que pode ser experimentada por meio dos jogos cooperativos. Esses jogos exploram as possibilidades de manifestações interpessoais, onde duas ou mais pessoas se ajudam para alcançar uma meta comum, de forma que o sucesso ou o insucesso seja vivenciado por todos (CARVALHO, 2015).

Na educação, o jogo é um recurso capaz de destacar os conceitos durante uma aprendizagem significativa e favorecer a retenção do conteúdo, mas, para tanto, precisa manter um equilíbrio entre as funções lúdicas e 
educativas. A função lúdica está associada à diversão e ao prazer/desprazer, e a educativa se refere à apreensão de saberes e conhecimentos (KISHIMOTO, 2016). No entanto, a utilização de jogos como materiais pedagógicos está associada a dois termos distintos: jogo educativo e jogo didático. Os jogos educativos envolvem ações ativas e dinâmicas no âmbito corporal, cognitivo, afetivo e social. Os jogos didáticos/educacionais estão diretamente relacionados ao ensino de conteúdos específicos (CUNHA, 2012). Os jogos educacionais também podem assumir um formato eletrônico. Os chamados "serious games" (ou "jogos sérios") são jogos eletrônicos projetados especificamente para treinamento profissional, gerenciamento de processos e ensinar crianças, jovens e adultos (BLACKMAN, 2005). Uma outra forma de trabalhar os elementos dos games com os estudantes é a "gamificação". Porém, "gamificar" não é apenas transformar uma atividade em um game. Segundo Kapp (2012, p. 10), a "[...] gamificação" pode ser definida como "a utilização de mecânica, estética e pensamento baseados em jogos para engajar pessoas, motivar a ação, promover a aprendizagem e resolver problemas".

\section{Jogos e brinquedotecas: em busca de uma taxonomia}

A origem dos jogos está relacionada com o sagrado, seja como inspiração divina para alegrar os homens ou como estratégia para conhecer os desejos dos deuses (VANZELLA, 2016). O Livro do Xadrez, Dados e Tábulas, organizado por D. Alfonso X, em 1283, apresenta os jogos como uma criação dos deuses para divertir os homens, e descreve a fábula dos jogos para serem jogados sentados, uma vez que ainda existiam os jogos praticados ao ar livre e a cavalo. No conto, um rei escuta de três sábios que proferem diferentes concepções sobre sorte, inteligência e oportunismo. O primeiro diz que mais vale a inteligência que a sorte, o segundo, que mais vale a sorte que a inteligência, e o terceiro, que o oportunismo se apropriaria da sorte e da inteligência. Após o rei solicitar aos sábios uma demonstração de seus pontos de vista, o primeiro apresenta o xadrez, o segundo os dados e o terceiro um jogo em que peças dispostas em casas dependiam do lançamento de dados para se movimentar (VANZELLA, 2016).

Uma das estratégias utilizadas pelos homens para desvendar os mundos ocultos do passado e do futuro foi transpor alguns de seus deuses-oráculos 
para grades quadriculadas que demonstravam o domínio sobre tempo e espaço. Dessa forma, os jogos de tabuleiro preservam sua origem sagrada devido à semelhança com planos canônicos de templos, claustros sagrados e cidades santas (VANZELLA, 2016). Os jogos de tabuleiro apresentam dois layouts em relação ao percurso: base quadrada e casas quadriculadas, e base quadrada ou redonda com um percurso em forma de labirinto que representa a evolução de um caminho espiritual (VANZELLA, 2016) (Figura 2).

\section{Figura 2}

\section{Tipos de percursos de jogos de tabuleiro}
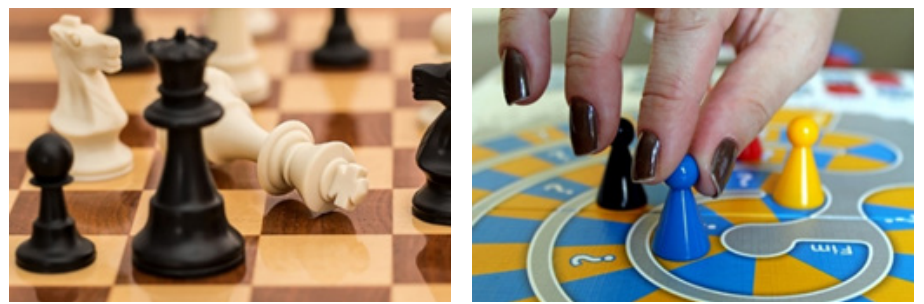

Fontes: hitps://pixabay.com/pt/photos/xeque-mate-xadrezpedido-de-demiss\%C3\%A3o-1511866/ /Imagem de Steve Buissinne por Pixabayl; https://pixabay.com/pt/photos/jogojogo-de-tabuleiro-jogo-perfil-588910. IImagem de Adriano Gadini por Pixabay).

Entre os jogos de tabuleiro mais antigos estão o Senet (3500 a.C. e 3100 a.C), o Real de Ur (2.500 a.C.), o Mancala (2000 a.C.), o Go (587 a.C.) e o Xadrez (400 d.C. e 600 d.C.). A origem do Xadrez parece estar associada ao jogo indiano Chaturanga que representava as quatro divisões do exército: infantaria (peão), cavalaria (cavalo), elefantes (bispo) e carruagens (torre) (KRUMMENAUER; STAUB JUNIOR; CUNHA, 2019; ROMÃO, 2008). A Revolução Industrial possibilitou a produção em massa dos jogos de tabuleiro. $O$ título que marcou a era moderna dos jogos de tabuleiro foi o Jogo da Vida (The Checkered Game of Life), lançado em 1860. Em 1935, surgiu o Banco Imobiliário (Monopoly), cujo objetivo era a compra e venda de terrenos. Em 1949, foi lançado o Detetive (Clue), que se passava numa mansão, onde os jogadores precisavam descobrir o assassino, o local e a arma utilizada para matar o dono da casa. Em 1957, o diretor de cinema francês Albert Lamorisse inventou o jogo La Conquête Du Monde, batizado no Brasil como War (ROMÃO, 2008). 
Os jogos de cartas são formato de jogo mais recente quando comparado aos jogos de tabuleiro, e muito popular em diferentes. Sua origem é incerta, mas se acredita que surgiu na China no século $X$, devido à invenção do papel pelos chineses. Em 1480, os franceses desenvolveram o design das cartas usadas na atualidade. As cartas reais são relacionadas a reis e figuras históricas, como Alexandre, o Grande (rei de paus), Carlos Magno (rei de copas), deusa grega Atena (dama de espadas) e Heitor - Príncipe de Troia (valete de ouros) (ROMÃO, 2008).

Atualmente, os jogos mais populares são os games. Em 1971, o primeiro arcade (ou fliperama) comercializado foi o jogo Spacewar! Mas, a dificuldade do jogo não contribuiu com a sua popularidade (ROMÃO, 2008). Com o passar dos anos, os videogames evoluíram e seus jogos se tornaram mais bonitos e complexos. As inovações advindas de títulos famosos, como a adição do pulo e de itens que aumentam o poder do personagem (Donkey Kong), o acréscimo do segundo jogador e de inimigos (Mario Bros. - arcade), os controles precisos e os cenários sofisticados (Super Mario Bros.), estágios temáticos que terminam com chefões (Mega Man), estimularam o desenvolvimento de jogos mais criativos e dinâmicos (ROGERS, 2016). O quadro abaixo

12 mostra a evolução dos consoles de videogame e alguns jogos populares que podem servir como referências para a construção de games e "serious games".

\section{Quadro 1}

Jogos e consoles populares a cada geração de videogames

\begin{tabular}{|c|c|c|}
\hline Geração & Consoles mais populares & Jogos famosos \\
\hline 1 & Magnavox Odyssey (1972) & Table Tennis, Ski, Shooting \\
Gallery
\end{tabular}


Felipe do Espírito Santo Silva-Pires | Valéria da Silva Trajanol Tania Cremonini de Araujo-Jorge

\section{Quadro 1}

Jogos e consoles populares a cada geração de videogames (continuação)

\begin{tabular}{|c|c|c|}
\hline Geração & Consoles mais populares & Jogos famosos \\
\hline 5 & $\begin{array}{c}\text { Playstation (1994), Sega Saturn } \\
\text { (1994), Nintendo 64 (1996) }\end{array}$ & $\begin{array}{c}\text { Crash Bandicoot, Final Fantasy } \\
\text { VII, Metal Gear Solid, Resident } \\
\text { Evil, Super Mario 64 }\end{array}$ \\
\hline 6 & $\begin{array}{c}\text { Sega Dreamcast (1998), } \\
\text { Playstation 2 (2000), Nintendo } \\
\text { Game Cube (200 1), Xbox } \\
\text { (200 1) }\end{array}$ & $\begin{array}{c}\text { God of War, GTA San Andreas, } \\
\text { Halo, Shadow of the Colossus }\end{array}$ \\
\hline 7 & $\begin{array}{c}\text { Xbox 360 (2005), Playstation 3 } \\
(2006) \text {, Nintendo Wii (2006) }\end{array}$ & $\begin{array}{c}\text { BioShock, The Last of Us, Red } \\
\text { Dead Redemption }\end{array}$ \\
\hline 8 & $\begin{array}{c}\text { Wii U (20 12), PlayStation 4 4 } \\
(2013), \text { Xbox One (2013) }\end{array}$ & $\begin{array}{c}\text { Cuphead, Marvel's Spider-Man, } \\
\text { Metal Gear Solid V, Rise of the } \\
\text { Tomb Raider }\end{array}$ \\
\hline
\end{tabular}

Fonte: Elaborado pelos autores.

Diante da grande quantidade de jogos disponíveis, alguns autores se preocuparam em construir diferentes formas de classificar objetos lúdicos para facilitar a escolha e melhor compreender o brincar, principalmente em brinquedotecas e centros de cultura lúdica. A elaboração de categorias de objetos lúdicos teve início no século XVI com François Rabelais (1494-1553) e Peter Brueguel (1525-1569). Na década de 1950, Jean Piaget e Roger Caillois criaram sistemas de classificação distintos para agrupar os jogos (AZEVEDO, 2016). Piaget (2010) organizou os jogos em 3 classes que se realizam de acordo com o desenvolvimento humano: exercícios (sensório-motores), simbólicos (pré-operatório) e regras (operatório concreto). Segundo Piaget, também existem os jogos de acoplagem (ou construção), que ocorrem durante uma fase de transição entre os outros tipos de jogos e não constituem uma nova classe. Nesse caso, o objeto que antes tinha um valor simbólico passa a ser utilizado na construção do brinquedo imaginado. Caillos (2017) sistematizou os jogos em 4 categorias: agôn (competitivos), alea (sorte), mimicry (representação) e illinix (pânico/vertigem). Caillois criou também duas categorias antagônicas para complementar seu sistema de classificação, a paidia (improvisados) e o ludus (regras). 
No século XX, também foram criados os sistemas ICCP (Internacional Council for Child's Play), apresentado por André Michelet (MICHELET, 1998), e - ESAR, desenvolvido por Denise Garon (1998). O sistema de classificação de jogos e brinquedos ICCP considera dois aspectos complementares: famílias de brinquedos (primeira idade, atividades físicas, atividades intelectuais, mundo técnico, desenvolvimento afetivo, atividades criativas e relações sociais) e classificação psicológica (desenvolvimento corporal, intelectual, afetivo, criativo e social) (MICHELET, 1998). No sistema de classificação e análise de materiais lúdicos ESAR, os jogos são categorizados por seis facetas: A latividades lúdicas), B (inteligência), C (habilidades funcionais), D (comportamentos sociais), $E$ (habilidades de linguagem) e $F$ (condutas afetivas). A faceta A é a mais importante, pois, além de nomear o sistema, define as categorias de jogos de acordo com a classificação proposta por Piaget (exercício, simbólico, acoplagem e regras). Após ser classificado na faceta $A$ o objeto é submetido a todas as outras facetas e descrito por completo (GARON, 1998). Em 2002, o centro Quais des Ludes, coordenado por Odile Périno, apresentou o sistema de classificação $\mathrm{COL}$ (Classement des Objets Ludiques). $O$ sistema $\mathrm{COL}$ é baseado no ESAR e, consequentemente, nas ideias de Piaget, porém sua categorização 14 é mais simples. O objeto é agrupado em uma classe (exercício, simbólico, acoplagem e regras) e, posteriormente, em subclasses a fim de receber uma codificação (AZEVEDO, 2016).

\section{Um olhar crítico sobre aprendizagem significativa e escolha/ construção de jogos}

Moreira (2000, 2005) propôs a construção de uma aprendizagem significativa "subversiva" ou "crítica" que respondesse de forma mais eficaz aos avanços de um mundo em constante transição, tomando como ponto de partida o princípio ausubeliano de que "aprendemos a partir do que já sabemos", e das ideias de Neil Postman e Charles Weingartner sobre o "ensino como uma atividade subversiva". Entretanto, a aprendizagem significativa subversiva apresenta alguns princípios necessários para o seu desenvolvimento.

A aprendizagem significativa subversiva tem como princípios norteadores: a importância do conhecimento prévio do sujeito (1. princípio do conhecimento prévio); a interação entre professor e estudante por meio de 
perguntas (2. princípio da interação social e do questionamento); a utilização de materiais instrucionais diversificados (3. princípio da não centralidade do livro de texto); a ideia de que o conhecimento é percebido e interpretado pelo sujeito (4. princípio do aprendiz como preceptor/representador); a linguagem como a chave para a compreensão do conteúdo 15. princípio do conhecimento como linguagem); os significados atribuídos pelas pessoas ao que está sendo ensinado (6. princípio da consciência semântica.); a busca e a correção de erros durante a aprendizagem (7. princípio da aprendizagem pelo erro); a não utilização de um subsunçor que impeça a captação dos significados compartilhados de um novo conhecimento (8. princípio da desaprendizagem); aprender a importância das perguntas como instrumentos de percepção, e das definições e metáforas como instrumentos para pensar (9. princípio da incerteza do conhecimento); a utilização de estratégias de ensino diversificadas que promovam a participação do estudante (10. princípio da não utilização do quadro-de-giz); o diálogo como estratégia básica de ensino (1 1. princípio do abandono da narrativa) (MOREIRA, 2005).

A escolha dos jogos educacionais que serão utilizados em sala de aula também exige um olhar crítico dos docentes com relação ao potencial do material como motivador e facilitador da construção do conhecimento. Há uma tendência em utilizar jogos de entretenimento consagrados para trabalhar diferentes conteúdos sem incorporar à estrutura central do jogo o objeto de conhecimento. Nos jogos de entretenimento o objeto de conhecimento está sempre a favor da diversão, ou seja, o que se espera que os jogadores aprendam constitui a própria natureza do jogo. Nos jogos pedagógicos o objeto de conhecimento não costuma ser parte fundamental do jogo, que pode ser descartado ou substituído. Alguns elementos são meramente ilustrativos, criados para atrair a atenção dos jogadores (COSTA, 2010). Segundo Costa, existem sete princípios que devem ser obedecidos para que jogos com fins pedagógicos se tornem efetivos como os jogos de entretenimento. São eles:

1. Um jogo com fim pedagógico deve possuir pelo menos uma estrutura similar ou comum à estrutura do objeto de conhecimento; 2. Essa estrutura do jogo deve ser perceptível ao jogador enquanto - joga; 3. A aprendizagem dessa estrutura deve ser indispensável para que se atinja o(s) objetivo(s) do jogo; 4. Em um jogo com fim pedagógico, tudo deve estar a favor da diversão e do entretenimento; 5. O objeto de conhecimento deve estar relacionado ao jogo a que pertence por relações estruturais essenciais (relações p) 
em prol da diversão e do entretenimento dos jogadores; 6 . No que depender do seu objeto de conhecimento, um jogo com fim pedagógico deve ser uma forma essencial de jogo; 7. Um jogo com fim pedagógico deve ser, pelo menos para o seu público-alvo, melhor como jogo do que qualquer uma de suas partes ou a simples soma delas (COSTA, 2010, p. 108).

A construção de jogos lentretenimento, educacionais, games, "serious games") deve considerar que a maioria dos designs se baseia em uma estrutura conhecida e o importante é adicionar elementos que possam conferir originalidade para o produto em desenvolvimento (ROGERS, 2016). Transformar uma ideia num protótipo, e posteriormente num jogo finalizado, é um processo trabalhoso que envolve história, "gameplay" e arte (KOSTER, 2013).

Os jogos se baseiam em uma história que sempre tem começo, meio e fim, e mesmo jogos que não precisam envolver o jogador apresentam uma certa narrativa (ordem de eventos). No entanto, a narrativa do jogador pode ser diferente da história do jogo, o que destaca a importância de se criar múltiplas narrativas. A história deve ser atrativa e os desenvolvedores precisam tomar cuidado para não dificultar a compreensão dos jogadores (ROGERS, 16 2016).

As ações realizadas pelo jogador durante a partida (saltar, lutar, coletar, escalar, explorar, agir furtivamente) são chamadas de "gameplay" (ou jogabilidade) e se relacionam com elementos do jogo, como níveis, perigos e inimigos. Habilidades e equipamentos específicos podem auxiliar o jogador, tornando os desafios/perigos e o confronto com os inimigos mais emocionantes e divertidos. Os jogos devem ser desafiadores, mas não excessivamente difíceis (ROGERS, 2016). Segundo Koster (2013), os desafios são divertidos e os jogadores têm que identificar um padrão para superá-los. Esses padrões facilitam o entendimento e permitem que os jogadores encontrem um sentido na proposta do jogo. Contudo, os padrões não devem ser muito complexos, a ponto de irritar o jogador, ou simples demais, acabando com a diversão. Isso também se aplica aos desafios que têm que ser compatíveis com o público-alvo. A conquista de um desafio nos leva a um "sentimento de realização" proporcionado pela liberação de endorfina no organismo (KOSTER, 2013). Essa sensação de prazer e bem-estar nos remete à diversão. 
Felipe do Espírito Santo Silva-Pires | Valéria da Silva Trajanol Tania Cremonini de Araujo-Jorge

A arte se apresenta nos jogos de diferentes maneiras. A logomarca comunica o gênero do jogo por meio de cores, formas e texto. As ilustrações retratam a narrativa, desde a criação dos personagens até elementos gráficos da interface. As ilustrações também promovem o jogo por meio de pôsteres, arte de capa, wallpapers e banners. Os jogos ainda utilizam filmes interativos, animações em Flash, desenhos e stop-motions para apresentar momentos grandiosos da narrativa, além de som e música para agregar realismo e interatividade a ações importantes durante a partida (ROGERS, 2016).

\section{Considerações Finais}

A Teoria da Aprendizagem Significativa é um referencial básico para o ensino, pois suas etapas vão do planejamento à prática e sempre consideram o papel retroalimentador das avaliações e a evolução do conhecimento do estudante. A Teoria fornece meios que facilitam os processos de ensino e aprendizagem, da mesma forma que reforça a importância da comunicação entre professor e aluno e da escolha criteriosa acerca do conteúdo.

$\bigcirc$ jogo faz parte da história da humanidade e seu potencial como facilitador dos processos de ensino e aprendizagem está associado ao uso de uma linguagem clara e objetiva. Os jogos educacionais favorecem a interação entre docente e discente, assim como entre discentes, pois a ludicidade propicia a construção de um ambiente dialógico. As partidas possibilitam momentos de tensão e alegria, e a aprendizagem ocorre mediante os erros e acertos decorrentes da tentativa de vencer os desafios impostos pelo jogo. Além disso, os jogos educacionais não se restringem a informações contidas nos livros, mas abarcam a cultura, fator primordial para a construção da estrutura cognitiva do aprendiz.

Os princípios da Teoria da Aprendizagem Significativa dialogam e interagem com o conceito e as propriedades dos jogos. $\bigcirc$ jogo trabalha diversos aspectos associados à cognição e às funções sensoriais e motoras e configura-se como um elemento de aprendizagem, tanto para docentes como para discentes. Os jogos educacionais podem facilitar os processos de ensino e aprendizagem por meio da apresentação, negociação e compartilhamento de significados. As informações apreendidas permitem a construção e/ou a produção de novos conhecimentos práticos ou teóricos contribuindo com o 
desenvolvimento cognitivo do educando de forma contextualizada. Os jogos educacionais promovem a formação de vestígios estáveis por meio da integração de diferentes linguagens - textual, visual e sensorial - facilitando o resgate do conteúdo a longo prazo. Portanto, o jogo possibilita a interação, não-arbitrária e substantiva, entre uma nova informação e o conhecimento preexistente do indivíduo, resultando em uma aprendizagem significativa.

\section{Referências}

AMORIM, Roseane Maria de; SILVA, Cintia Gomes da. $O$ uso das imagens no ensino de história: reflexão sobre o uso e a interpretação das imagens dos povos indígenas. História \& Ensino, Londrina, v. 22, n. 2, p. 165-187, 2016.

AUSUBEL, David Paul. Aquisição e retenção de conhecimentos: uma perspectiva cognitiva. Lisboa: Editora Plátano, 2003.

AUSUBEL, David Paul; NOVAK, Joseph Donald; HANESIAN, Helen. Psicologia educacional. Rio de Janeiro: Interamericana, 1980.

18 AZEVEDO, Gilles Henrique Tavares de. Classificações de objetos lúdicos: sistema COL na brinquedoteca. In: KISHIMOTO, Tizuko Morchida; SANTOS, Maria Walburga dos (org.). Jogos e brincadeiras: tempos, espaços e diversidade. São Paulo: Cortez, 2016.

BLACKMAN, Sue. Serious games... and less! Computer Graphics, New York, v. 39, n. 1, p. 12-16, 2005.

CAILLOIS, Roger. Os jogos e os homens: a máscara e a vertigem. Petrópolis: Vozes, 2017. CARVALHO, José Roberto Calçada. Competição e cooperação na educação física escolar. 2. ed. São Paulo: Perse, 2015.

COSTA, Leandro Demenciano. $\mathbf{O}$ que os jogos de entretenimento têm que os educativos não têm: 7 princípios para projetar jogos educativos eficientes. Teresópolis: Editora Novas Ideias, 2010.

CUNHA, Marcia Borin da. Jogos no ensino de química: considerações teóricas para sua utilização em sala de aula. Química Nova na Escola, São Paulo, v. 34, n. 2, p. 92-98, 2012.

DIAS, Marina Célia Moraes. Metáfora e pensamento: considerações sobre a importância do jogo na aquisição do conhecimento e implicações para a educação pré-escolar. In: 
KISHIMOTO, Tizuko Morchida (org.). Jogo, brinquedo, brincadeira e a educação. 14. ed. São Paulo: Cortez, 2011.

FREIRE, Paulo. Pedagogia do oprimido. 58. ed. Rio de Janeiro: Paz e Terra, 2014.

GAGLIARD, Raúl. Los conceptos estructurales en el aprendizaje por investigación. Revista Enseñanza de las ciencias, Barcelona, v. 4, n. 1, p. 30-35, 1986.

GARON, Denise. Classificação e análise de materiais lúdicos - $\bigcirc$ sistema ESAR. In: FRIEDMANN, Adriana (org.). O direito de brincar: a brinquedoteca. 4. ed. São Paulo: Scritta, 1998.

GOWIN, Bob. Educating. New York: Cornell University Press, 1981.

HUIZINGA, Johan. Homo ludens. 8. ed. São Paulo: Perspectiva, 2014.

KAPP, Karl. The gamification of learning and instruction: game-based methods and strategies for training and education. Nova Jersey: John Wiley \& Sons, 2012.

KISHIMOTO, Tizuko Morchida. O jogo e a educação infantil. In: KISHIMOTO, Tizuko Morchida (org.). Jogo, brinquedo, brincadeira e a educação. 14. ed. São Paulo: Cortez, 2011 .

KISHIMOTO, Tizuko Morchida. O jogo e a educação infantil. São Paulo: Cengage Learning, 2016.

KOSTER, Raph. A theory of fun for game design. 2. ed. Sebastopol: O'Reilly Media, 2013. KRUMMENAUER, Wilson Leandro; STAUB JUNIOR, Carlos Roberto; CUNHA, Michelle Brito. $\bigcirc$ Jogo de Xadrez como ferramenta de desenvolvimento do raciocínio lógico-matemático com alunos do $4^{\circ}$ ano do Ensino Fundamental. REMAT, Bento Gonçalves, v. 5, n. 2, p. $72-81,2019$.

LEMOS, Evelyse dos Santos. Enseñanza y el hacer docente: reflexiones a la luz de la teoría del aprendizaje significativo. Aprendizagem Significativa em Revista, Porto Alegre, v. 2, n. 2 , p. 23-41, 2012.

MAYER, Richard. Introduction to multimedia learning. In: MAYER, Richard (org.). The Cambridge handbook of multimedia learning. Cambridge: Cambridge University Press, 2005.

MICHELET, André. Classificação de jogos e brinquedos - A classificação I.C.C.P. In: FRIEDMANN, Adriana (org.). O direito de brincar: a brinquedoteca. 4. ed. São Paulo: Scritta, 1998. 
MOREIRA, Marco Antonio. Aprendizagem significativa subversiva. In: ENCONTRO INTERNACIONAL SOBRE APRENDIZAGEM SIGNIFICATIVA, 3., 2000, Peniche. Atas [...]. Peniche, 2000.

MOREIRA, Marco Antonio. Aprendizagem significativa crítica. Porto Alegre: Instituto de Física da UFRGS, 2005.

MOREIRA, Marco Antonio. Teorias de aprendizagem. 2. ed. São Paulo: Editora Pedagógica e Universitária Ltda, 2011.

NOVAK, Joseph Donald. A theory of education. New York: Cornell University Press, 1977.

NOVAK, Joseph Donald. Aprender, criar e utilizar o conhecimento: mapas conceituais como ferramentas de facilitação nas escolas e empresas. Lisboa: Plátano, 2000.

NOVAK, Joseph Donald. A theory of education: meaningful learning underlies the constructive integration of thinking, feeling, and acting leading to empowerment for commitment and responsibility. Aprendizagem Significativa em Revista, Porto Alegre, v. 1, n. 2, p. 1-14, 2011.

OlIVEIRA, Mônica de Moraes; SOUZA, Sandra Maria Ribeiro de. O caráter multidisciplinar da comunicação visual em hospitais. Comunicação e Inovação, São Caetano do Sul, v. 15, n. 29, p. 159-170, 2014.

PIAGET, Jean. A formação do símbolo na criança. 4. ed. Rio de Janeiro: LTC, 2010.

ROGERS, Scott. Level up: um guia para o design de grandes jogos. São Paulo: Blucher, 2016.

ROMÃO, João Jair da Silva. Estudo sobre interfaces gráficas digitais para jogos e atividades lúdicas. 2008. Trabalho de Conclusão de Curso (Bacharelado em Design) - Universidade Federal de Santa Catarina, Florianópolis, 2008.

SCHWAB, Joseph. The practical 3: translation into curriculum. The School Review, Chicago, v. 81, n. 4, p. 501-522, 1973.

VANZELLA, Lila Cristina Guimarães. Jogos de tabuleiro: análise na perspectiva histórica. In: KISHIMOTO, Tizuko Morchida; SANTOS, Maria Walburga dos (org.). Jogos e brincadeiras: tempos, espaços e diversidade. São Paulo: Cortez, 2016. 
Prof. Dr. Felipe do Espirito Santo Silva-Pires Instituto Oswaldo Cruz/Fiocruz (Brasil) Laboratório de Inovações em Terapias, Ensino e Bioprodutos Orcid id: https:/ / orcid.org/0000-0002-040 1-1589 E-mail: felipesilvapires@yahoo.com.br

Profa. Dra. Valéria da Silva Trajano Instituto Oswaldo Cruz/Fiocruz (Brasil) Laboratório de Inovações em Terapias, Ensino e Bioprodutos Orcid id: https:/ / orcid.org/0000-0002-7972-7899 E-mail: virtrajano@gmail.com

Profa. Dra. Tania Cremonini de Araujo-Jorge Instituto Oswaldo Cruz/Fiocruz (Brasil) Laboratório de Inovações em Terapias, Ensino e Bioprodutos Orcid id: https: / / orcid.org/0000-0002-8233-5845 E-mail: taniaaravjojorge@gmail.com

Recebido 26 maio 2020 Aceito 10 jun. 2020 